\title{
The Once-Daily Human Glucagon-Like Peptide-1 (GLP-1) Analog Liraglutide Improves Postprandial Glucose Levels in Type 2 Diabetes Patients
}

Anne Flint · Christoph Kapitza · Charlotte Hindsberger · Milan Zdravkovic

Received: November 29, 2010 / Published online: February 17, 2011

(C) The Author(s) 2011. This article is published with open access at Springerlink.com

\section{ABSTRACT}

Introduction: Fasting and postprandial plasma glucose (FPG, PPG) control are both necessary to achieve glycosylated hemoglobin $\left(\mathrm{HbA}_{1 \mathrm{c}}\right)$ regulation goals. Liraglutide, based on its glucagon-like peptide 1 (GLP-1)-mediated pharmacology and pharmacokinetics may reduce $\mathrm{HbA}_{1 \mathrm{c}}$ through both FPG and PPG levels. The objective of the present study was to investigate the effect of once-daily liraglutide $(0.6,1.2$, and $1.8 \mathrm{mg})$ at steady state on FPG, PPG, postprandial insulin, and gastric emptying. Methods: Eighteen subjects with type 2 diabetes, aged 18-70 years, with a body mass index of $18.5-40 \mathrm{~kg} / \mathrm{m}^{2}$ and $\mathrm{HbA}_{1 \mathrm{c}}$ of $7.0 \%-9.5 \%$ were included in this single-centre, randomized, placebo-controlled, double-blind, two-period, cross over trial. Patients were randomized into

Anne Flint $(\bowtie)$

Novo Nordisk A/S, Vandtårnsvej 108-110, 2860 Søborg, Denmark. Email: aflt@novonordisk.com

Anne Flint · Charlotte Hindsberger · Milan Zdravkovic Novo Nordisk A/S, Copenhagen, Denmark

Christoph Kapitza

PROFIL Institut für Stoffwechselforschung $\mathrm{GmbH}$, Neuss, Germany two groups (A or B). Group A received oncedaily liraglutide for 3 weeks, followed by a 3-4-week washout period and 3 weeks of oncedaily placebo. Group B was treated as for Group A, but treatment periods were reversed (ie, placebo followed by liraglutide). A meal test was performed at steady-state liraglutide/placebo doses of $0.6,1.2$, and $1.8 \mathrm{mg} /$ day. Plasma glucose, insulin, and paracetamol (acetaminophen) concentrations (to assess gastric emptying) were measured pre- and postmeal. Results: PPG levels significantly decreased $(P<0.001)$ after all three liraglutide doses when compared with placebo. This decrease was also apparent when corrected for baseline (incremental excursions), with the exception of average incremental increase calculated as area under the concentration curve (AUC) over the fasting value from time zero to 5 hours (i $A U C_{0-5 \mathrm{~h}} / 5$ hours) after liraglutide $0.6 \mathrm{mg}$, where there was a trend to decrease $(P=0.082)$. In addition, FPG levels significantly decreased at all three liraglutide dose levels when compared to placebo $(P<0.001)$. Fasting and postprandial insulin levels significantly increased with liraglutide versus placebo at all doses studied $(P<0.001)$. A significant delay in gastric emptying during the first hour postmeal was observed at the two highest liraglutide 
doses versus placebo. Conclusion: In addition to lowering FPG levels, liraglutide improves PPG levels (absolute and incremental) possibly by both stimulating postprandial insulin secretion and delaying gastric emptying.

Keywords: exenatide; gastric emptying; incretin; insulin; type 2 diabetes mellitus

\section{INTRODUCTION}

Type 2 diabetes is a progressive disease characterized by decreased insulin sensitivity and deteriorating beta-cell insulin secretion. ${ }^{1}$ It has also been found that impaired incretin function due to a decrease in the levels and the insulinotropic effects of the incretin hormones could be an important factor. ${ }^{2,3}$

Intensive treatment to achieve good glycemic control, as assessed by glycosylated hemoglobin $\left(\mathrm{HbA}_{1 \mathrm{c}}\right)$ levels, can significantly reduce the risk of type 2 diabetes complications. ${ }^{4,5}$ As $\mathrm{HbA}_{1 \mathrm{c}}$ is a measure of average fasting and postprandial plasma glucose (FPG, PPG) levels, ${ }^{6}$ therapies that target both contributors are necessary to achieve optimal glycemic control. ${ }^{7}$

The incretin hormones glucagon-like peptide 1 (GLP-1) and glucagon-dependent insulinotropic polypeptide (GIP) are released in the intestine shortly after nutrient ingestion, and are responsible for mediating the incretin effect (ie, the enhanced insulin secretion observed after oral glucose administration, compared with an isoglycemic intravenous challenge). ${ }^{8,9}$ GLP-1 has been shown to be a physiological modulator of gastric motility, ${ }^{10}$ and the inhibitory effect of exogenous GLP-1 on gastric emptying has been demonstrated in healthy subjects, ${ }^{11,12}$ as well as in patients with type 2 diabetes. ${ }^{13,14}$ GLP-1 has been shown to have diverse effects on gastrointestinal functions in humans, such as relaxation of the proximal stomach, inhibition of antroduodenal contractility, and stimulation of pyloric motility. ${ }^{10,12,13,15-18}$ Precisely how GLP-1 mediates these effects on gastric emptying however (ie, centrally or peripherally mediated) is not known, and further studies are required to elucidate such mechanisms. ${ }^{10}$

Exenatide $^{19}$ and liraglutide ${ }^{20}$ share the ability to slow gastric emptying. However, this effect has yet to be shown with clinically relevant doses of liraglutide, and this was part of the aim of our study.

The physiological actions of GLP-1 are preserved in individuals with type 2 diabetes, ${ }^{21,22}$ giving this molecule great potential as a therapeutic agent. Unfortunately, native GLP-1 is rapidly degraded by the enzymes dipeptidyl peptidase 4 (DPP-4) and neutral endopeptidase (NEP). As a result, the plasma half-life $\left(t_{1 / 2}\right)$ of intravenously administered GLP-1 is less than 2 minutes, ${ }^{23}$ which greatly limits its potential as a therapeutic agent. ${ }^{24}$ Hence, to fulfill the potential of GLP-1 as a therapeutic option in type 2 diabetes, GLP-1 analogs or mimetics with longer lifetimes have been developed. Liraglutide is a GLP-1 analog that shares 97\% of its amino-acid sequence with native GLP-1. Additionally, a 16-carbon acyl chain has been attached to lysine 26 through a linker residue, which allows reversible binding to albumin. ${ }^{23}$ As a result, liraglutide is slowly released from the injection site, self-associates, and has decreased susceptibility to DPP-4 degradation in the bloodstream, prolonging the $t_{1 / 2}$ of the analog to around 13 hours, which makes it suitable for once-daily administration. ${ }^{25}$

Clinical trials have shown that liraglutide significantly reduces $\mathrm{FPG}$ and $\mathrm{HbA}_{1 \mathrm{c}}$ with concomitant weight loss and a low risk of hypoglycemia in type 2 diabetes. ${ }^{26-33}$ However, the effect of liraglutide on postprandial incremental glucose concentrations has not been investigated during standardized 
conditions. The primary aim of this study was therefore to investigate the potential effect of once-daily liraglutide at steady state on PPG during standardized conditions. Furthermore, the effect of liraglutide on FPG, insulin levels, and gastric emptying was investigated. One hypothesis of this study was that liraglutide would lead to decreased PPG and FPG levels, increased insulin levels, and delayed gastric emptying.

\section{METHODS}

\section{Design of Study}

This was a single-center, randomized, placebocontrolled, double-blind, two-period, crossover trial, comparing the effect of steady-state liraglutide at three dose levels $(0.6,1.2$, and $1.8 \mathrm{mg}$ /day) versus placebo on the responses of FPG and PPG, insulin, and gastric emptying in individuals with type 2 diabetes.

After an appropriate washout period of at least 3 weeks for patients previously treated with oral antidiabetic drugs (OAD), patients were randomly assigned to treatment group A (3 weeks of once-daily liraglutide, 3-4 weeks of washout, and 3 weeks of once-daily placebo) or B (3 weeks of once-daily placebo, 3-4 weeks of washout, and 3 weeks of once-daily liraglutide). During the 3-week treatment periods, the liraglutide/ placebo dose was escalated weekly in $0.6 \mathrm{mg}$ increments from $0.6 \mathrm{mg}$ until a dose of $1.8 \mathrm{mg}$ daily was reached. Assessments were performed after 1, 2, and 3 weeks during the treatment periods, thus providing pharmacodynamic (PD) measures for steady-state $0.6,1.2$, and $1.8 \mathrm{mg}$ liraglutide doses. As the subjects had not been treated for equivalent periods of time with either liraglutide (each dose) or placebo at the time of assessment, any comparisons made between the doses were considered as purely explorative.

\section{Safety Considerations}

Any adverse events (AEs) that occurred during the trial were treated by established standards of care. All AEs were followed up until the subject recovered or stabilized or until the last visit (whichever came first).

FPG was measured every other day during the trial. If FPG levels rose above $14 \mathrm{mmol} / \mathrm{L}$ in two consecutive measurements, an additional check was performed 1-3 days later. If FPG remained above $14 \mathrm{mmol} / \mathrm{L}$ the subject was withdrawn from the trial.

\section{Subjects}

Individuals included in the trial were men or women with type 2 diabetes, aged 18-70 years, with a body mass index (BMI) of $18.5-40 \mathrm{~kg} / \mathrm{m}^{2}$, and $\mathrm{HbA}_{1 \mathrm{c}}$ of $7.5 \%-9.5 \%$ (if treated with diet only), or $7.0 \%-9.5 \%$ (if treated with OADs). Treatment with metformin or alpha-glucosidase inhibitors in monotherapy was allowed as OAD treatments.

Two exclusion criteria were established to remove subjects who exhibited: (1) clinically significant active cardiovascular disease, and (2) significant gastrointestinal disease, including, but not limited to, apparent diabetic gastroparesis, diabetic diarrhea, and surgery of the gastrointestinal tract (except appendectomy). Further conditions warranting exclusion from the trial were impaired liver or renal function, hypertension, recurrent severe hypoglycemia, human immunodeficiency virus (HIV)-positive antibody status, active hepatitis $\mathrm{B}$ or $\mathrm{C}$, and the use of any substances that could interfere with the results of the trial.

All subjects gave their written consent prior to any study-related activities. The study was conducted in accordance with the Declaration of Helsinki. ${ }^{34}$ The study protocol and informed consent forms were approved by the Federal 
Institute for Drugs and Medical Devices in Bonn, Germany, and by the Ethics Commission of the Ärztekammer Nordrhein in Düsseldorf, Germany.

\section{Liraglutide Administration}

Liraglutide or a corresponding volume of placebo was administered subcutaneously in the abdomen once-daily in the evening, using a prefilled disposable pen device ( $3 \mathrm{ml}$ FlexPen ${ }^{\circledR}$; Novo Nordisk A/S, Copenhagen, Denmark).

\section{Test Day, Meal Description, and Sample Collection}

On test days, subjects were asked to report to the clinic at 07:00 hours, having fasted since 20:00 hours the previous evening. Before the test meal, blood samples for baseline measurements of plasma glucose, insulin, and paracetamol (for the assessment of gastric emptying) were drawn. Subjects were served a standardized breakfast consisting of usual and local food items with a fixed energy and macronutrient content ( 2 megajoules $(\mathrm{MJ}), 50$ energy percentage $(\mathrm{E} \%)$ from carbohydrates, $35 \mathrm{E} \%$ from fat, and 15 $\mathrm{E} \%$ from protein). Breakfast was served at 08:30 hours (time $=0$ ) and ingested within 15 minutes. Along with the meal, patients also received paracetamol $1.5 \mathrm{~g}$. Paracetamol is not absorbed in the stomach, but is rapidly and almost completely absorbed in the intestine/duodenum, so the rate of paracetamol absorption can be used as an index for gastric emptying. ${ }^{35,36}$ During the 5-hour postprandial period, blood was sampled frequently for measurements of PPG, insulin, and paracetamol concentrations.

\section{Assessments}

To assess adherence to liraglutide injections, morning blood samples were collected at baseline (before dosing), and weekly during the test days $6,8,10$, and 12 hours after the liraglutide/ placebo dosing, which is around the time of the maximum concentration $\left(T_{\max }\right)$ of liraglutide. Vital signs, standard 12-lead electrocardiogram (ECG), physical examination, and blood and urine sampling for standard laboratory assessments were performed at screening and follow-up. The analyses of glucose, insulin, and liraglutide in plasma were performed by Capio Diagnostik A/S (now Unilabs A/S, Copenhagen, Denmark). A colorimetric assay, Glucose Hexokinase II (GLUH), from Bayer Healthcare (Bayer A/S, Lyngby, Denmark), was used for glucose, whereas enzyme-linked immunosorbent assay (ELISA) were used for insulin and liraglutide, described by Andersen et al., ${ }^{37}$ and Agersø et al.,25 respectively. The bioanalysis of paracetamol in plasma was conducted by AAIPharma Deutschland GmbH \& Co. KG (Neu-Ulm, Germany) by liquid chromatography tandem mass spectrometry (LS-MS/MS).

The primary endpoint derived from the plasma glucose profiles was the area under the concentration curve (AUC) from time zero (start of breakfast) to 5 hours $\left(A U C_{0-5 \mathrm{~h}}\right)$.

In addition, the following secondary endpoints were evaluated. For plasma glucose, average incremental increase calculated as AUC over the fasting value from time zero to 5 hours (iAUC $C_{0-5 \mathrm{~h}} / 5$ hours); glucose concentration 2 hours after starting the test meal $\left(C_{2 \mathrm{~h}}\right)$; fasting glucose concentration $\left(C_{0}\right)$; and AUC from time zero to 1 hour $\left(A U C_{0-1 \mathrm{~h}}\right)$. For plasma insulin, $\left(\mathrm{C}_{0}\right) ;\left(A U C_{0-1 \mathrm{~h}}\right)$ and $\left(A U C_{0-5 \mathrm{~h}}\right),\left(\mathrm{i} A U C_{0-5 \mathrm{~h}}\right) / 5$ hours; and maximum concentration $\left(C_{\max }\right)$. For gastric emptying based on plasma paracetamol $\left(A U C_{0-1 \mathrm{~h}}\right) ;\left(A U C_{0-5 \mathrm{~h}}\right)$; and $\left(C_{\max }\right)$.

Safety was assessed by AEs, hypoglycemic episodes, physical examination, vital signs, ECG, and laboratory parameters (hematology, biochemistry, and urinalysis). 


\section{Statistics}

Based on a paper by Le Floch et al., ${ }^{38}$ withinsubject standard deviation for AUC under the postprandial glucose curve among subjects with type 2 diabetes was found to be $280 \mathrm{mmol} \mathrm{min} / \mathrm{L}$, this value being an index of the duration and extent of elevated glucose concentration. With a clinically relevant difference corresponding to $20 \%$ of the observed AUC, it was calculated that the necessary number of subjects required to reject the hypothesis of no difference between liraglutide and placebo with a power of 0.9 was 14 .

The statistical analysis of PD endpoints was carried out using a linear normal model (analysis of variance [ANOVA]) that included an interaction effect between treatment period and test day, as well as liraglutide dose. Additionally, the model accounted for the correlation between within-subject observations. From this model, the contrast between liraglutide and placebo was estimated for each dose group. No formal comparison between doses was performed, as subjects had not been treated for equivalent periods of time with either liraglutide (all three doses) or placebo at the time of assessment. All AUC values were calculated by the linear trapezoidal method and were log transformed prior to statistical analysis, except incremental AUC data, where the untransformed values were used for the analysis. $C_{0}, C_{2}$ hours, and $C_{\max }$ were obtained as the observed value at baseline, after 2 hours, and as the maximum value over 5 hours, respectively. In addition, an explorative statistical analysis of the association between glucose $\mathrm{i} A U C_{0-1 \mathrm{~h}}$, and gastric emptying measured by $\log$ (paracetamol $A U C_{0-1 \mathrm{~h}}$ ) was performed. All PD endpoints among subjects receiving liraglutide and subjects receiving placebo were compared by use of a two-sided test at a 5\% significance level (ie, $P<0.05$ ). All safety data were evaluated by the use of summary statistics.

\section{RESULTS}

\section{Subjects}

Eighteen subjects were included in the study. All subjects were white and 78\% $(n=14)$ were male. Age (mean \pm standard deviation [SD]) was $58.6 \pm 6.9$ years, BMI was $29.7 \pm 4.2 \mathrm{~kg} / \mathrm{m}^{2}$ and $\mathrm{HbA}_{1 \mathrm{c}}$ was $7.8 \pm 0.6 \%$. Most of the subjects $(n=16 ; 89 \%)$ were on OAD monotherapy before commencing the trial.

One subject had measurable concentrations of liraglutide during treatment with placebo. Therefore, data from the placebo treatment period of this subject were excluded.

\section{Glucose}

The absolute and baseline-corrected glucose timeconcentration profiles illustrate a decrease in FPG (Figure 1) and PPG concentrations (Figures 1 and 2) after treatment with liraglutide compared with placebo at all doses studied.

Figure 1. Mean postprandial plasma glucose (PPG) profiles during a meal test performed at steady-state liraglutide doses of $0.6,1.2$, and $1.8 \mathrm{mg}$ or placebo.

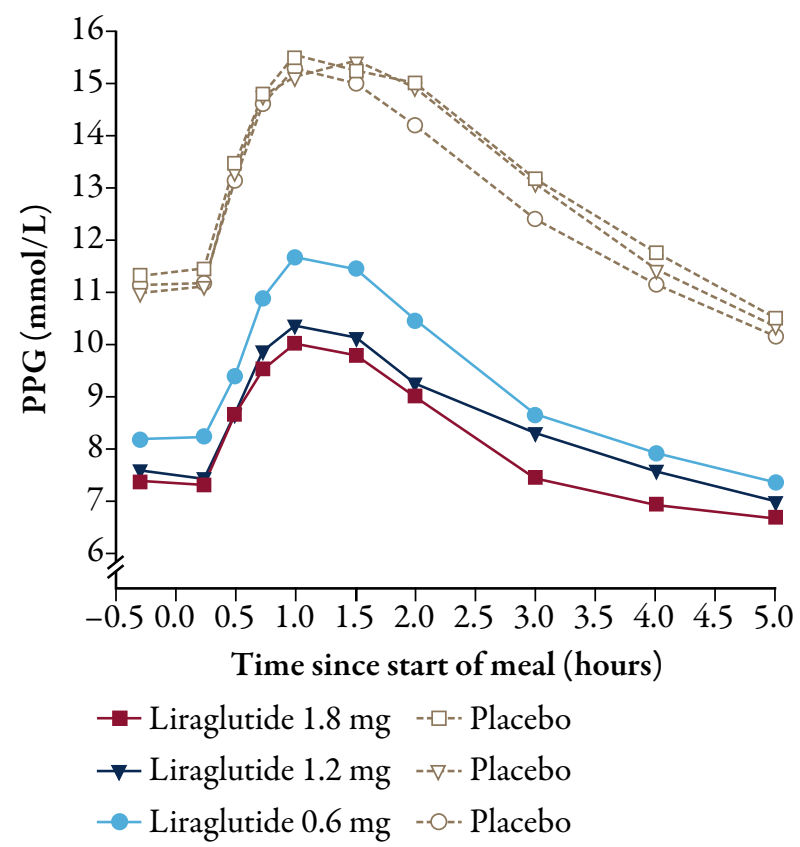


Figure 2. Mean baseline corrected postprandial plasma glucose (PPG) increment from baseline (0-5 hours) during a meal test performed at steady-state liraglutide doses of $0.6,1.2$, and $1.8 \mathrm{mg}$ or placebo.
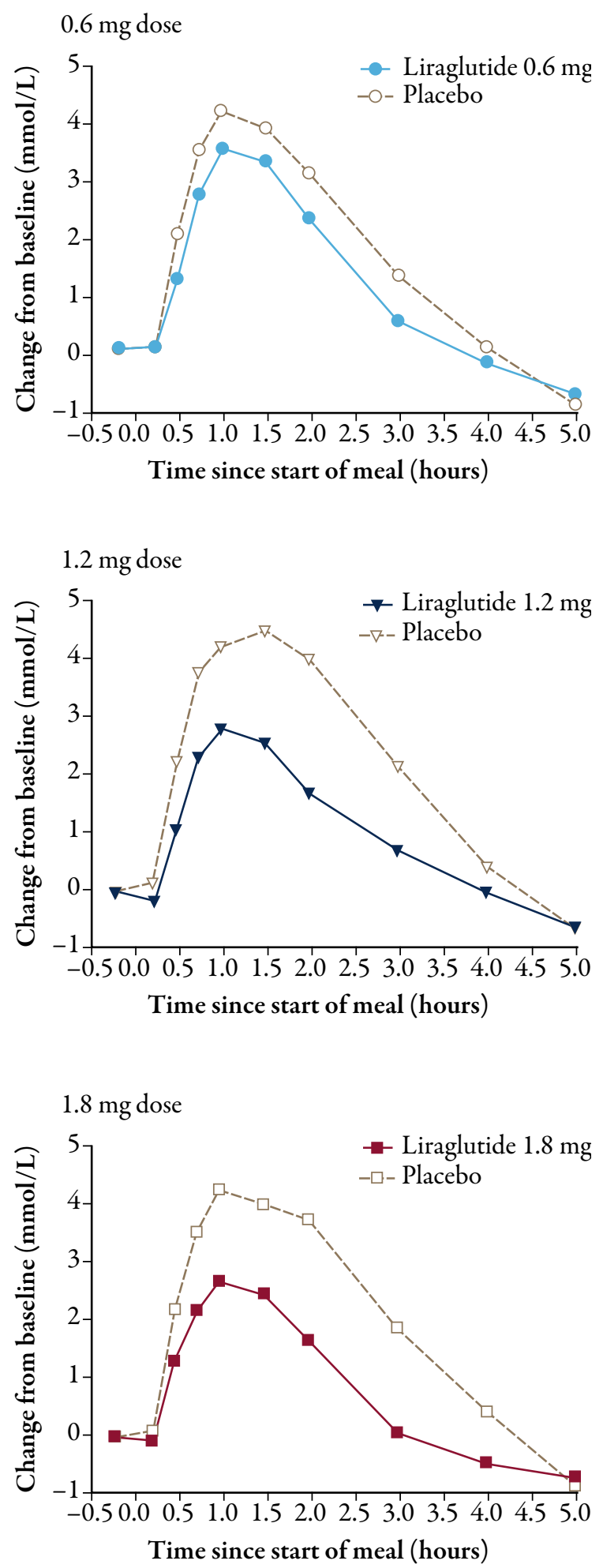

PPG

The statistical analysis confirmed a decrease in FPG as well as PPG levels after all three liraglutide doses when compared with placebo, except for $\mathrm{i} A U C_{0-5 \mathrm{~h}} / 5$ hours after liraglutide $0.6 \mathrm{mg}$, where the decrease did not reach statistical significance $(P=0.082)$ (Table 1$)$. The estimates of glucose $A U C_{0-5 \mathrm{~h}}$ were $39 \%, 35 \%$, and $27 \%$ lower after treatment with liraglutide 1.8, 1.2, and $0.6 \mathrm{mg}$, respectively, than after placebo, suggesting a slightly dose-dependent, glucoselowering effect. Estimates of glucose $A U C_{0-1 \mathrm{~h}}$ were also significantly reduced by a similar order after treatment with liraglutide 1.8, 1.2, and $0.6 \mathrm{mg}$, respectively, compared with placebo (Table 1). The mean PPG excursions, as assessed by estimates of $\mathrm{i} A U C_{0-5 \mathrm{~h}} / 5 \mathrm{~h}$, were $1.09 \mathrm{mmol} / \mathrm{L}$, $1.10 \mathrm{mmol} / \mathrm{L}$, and $0.45 \mathrm{mmol} / \mathrm{L}$ lower after liraglutide $1.8,1.2$, and $0.6 \mathrm{mg}$ treatment, respectively, than after placebo. Additionally, mean concentrations of plasma glucose 2 hours after breakfast $\left(C_{2 \mathrm{~h}}\right)$ were also significantly reduced at all liraglutide doses, compared with placebo (Table 1).

\section{FPG}

The difference in the starting point of the profiles in Figure 1 represents the effect of steady-state liraglutide doses of $0.6,1.2$, and $1.8 \mathrm{mg}$ on FPG. On average, this difference was 3-4 mmol/L lower with liraglutide than compared with placebo. The statistical analysis confirmed a significant decrease in FPG levels at all three liraglutide dose levels when compared with placebo $(P<0.001)$ (Table 1).

\section{Insulin}

$C_{0}$ was significantly higher with liraglutide than with placebo at all three doses, and 
Table 1. Comparison of glucose endpoints.

\begin{tabular}{|c|c|c|c|c|}
\hline & \multirow{2}{*}{$\begin{array}{l}\text { Liraglutide } \\
(\text { mean }[\mathrm{SD}])\end{array}$} & \multirow{2}{*}{$\begin{array}{c}\text { Placebo } \\
(\text { mean }[S D])\end{array}$} & \multicolumn{2}{|c|}{ Liraglutide versus placebo } \\
\hline & & & Estimate* (95\% CI) & $P$ value \\
\hline \multicolumn{5}{|c|}{ Fasting $C_{\text {glucose }, 0 \mathrm{~h}}(\mathrm{mmol} / \mathrm{L}) \dagger$} \\
\hline $0.6 \mathrm{mg}$ & $8.13(1.61)$ & $11.12(1.82)$ & $0.74(0.69,0.80)$ & $<0.001$ \\
\hline $1.2 \mathrm{mg}$ & $7.55(1.38)$ & $10.97(1.82)$ & $0.69(0.64,0.75)$ & $<0.001$ \\
\hline $1.8 \mathrm{mg}$ & $7.33(0.85)$ & $11.32(1.92)$ & $0.66(0.61,0.71)$ & $<0.001$ \\
\hline \multicolumn{5}{|c|}{$C_{\text {glucose } 2 \mathrm{~h}}(\mathrm{mmol} / \mathrm{L}) \dagger$} \\
\hline $0.6 \mathrm{mg}$ & $10.44(2.60)$ & $14.22(2.85)$ & $0.73(0.64,0.82)$ & $<0.001$ \\
\hline $1.2 \mathrm{mg}$ & $9.24(2.66)$ & $14.95(2.10)$ & $0.60(0.53,0.68)$ & $<0.001$ \\
\hline $1.8 \mathrm{mg}$ & $8.98(1.54)$ & $15.04(2.76)$ & $0.60(0.53,0.68)$ & $<0.001$ \\
\hline \multicolumn{5}{|c|}{$A U C_{\text {glucose }, 0-1 \mathrm{~h}}(\mathrm{mmol} \mathrm{min} / \mathrm{L}) \dagger$} \\
\hline $0.6 \mathrm{mg}$ & $574.11(94.54)$ & $781.76(120.73)$ & $0.74(0.68,0.80)$ & $<0.001$ \\
\hline $1.2 \mathrm{mg}$ & $522.20(89.79)$ & $781.59(106.47)$ & $0.67(0.62,0.73)$ & $<0.001$ \\
\hline $1.8 \mathrm{mg}$ & $510.63(77.05)$ & $797.34(128.55)$ & $0.64(0.60,0.70)$ & $<0.001$ \\
\hline \multicolumn{5}{|c|}{$A U C_{\text {glucose }, 0-5 \mathrm{~h}}(\mathrm{mmol} \mathrm{min} / \mathrm{L}) \dagger$} \\
\hline $0.6 \mathrm{mg}$ & $2772(608)$ & $3818(712)$ & $0.73(0.66,0.80)$ & $<0.001$ \\
\hline $1.2 \mathrm{mg}$ & $2554(570)$ & $3927(573)$ & $0.65(0.59,0.71)$ & $<0.001$ \\
\hline $1.8 \mathrm{mg}$ & $2414(392)$ & $3974(760)$ & $0.62(0.56,0.68)$ & $<0.001$ \\
\hline \multicolumn{5}{|c|}{$\mathrm{i} A U C_{\text {glucose, } 0-5 \mathrm{~h} / 5 \mathrm{~h}}(\mathrm{mmol} / \mathrm{L}) \dagger$} \\
\hline $0.6 \mathrm{mg}$ & $1.44(0.80)$ & $1.92(1.18)$ & $-0.45(-0.97,0.06)$ & 0.082 \\
\hline $1.2 \mathrm{mg}$ & $1.18(0.65)$ & $2.27(1.00)$ & $-1.10(-1.62,-0.58)$ & $<0.001$ \\
\hline $1.8 \mathrm{mg}$ & $1.02(0.58)$ & $2.15(0.95)$ & $-1.09(-1.61,-0.58)$ & $<0.001$ \\
\hline
\end{tabular}

${ }^{*}$ Estimates are ratios except $A U C_{\text {glucose, } 0-1 \mathrm{~h}}$ and ${ }_{\text {iAUCglucose }, 0-5 \mathrm{~h}} / 5 \mathrm{~h}$, which are differences.

†Conversion factor to $\mathrm{mg} / \mathrm{dL}: \times 18$.

$A U C=$ area under the curve; $C_{\text {glucose }}=$ glucose concentration; $\mathrm{CI}=$ confidence intervals; $\mathrm{SD}=$ standard deviation.

mean $C_{\max }$ was significantly higher with liraglutide $0.6 \mathrm{mg}$ and $1.8 \mathrm{mg}$ than with placebo (Figure 3 ). The estimates of insulin $A U C_{0-5 \mathrm{~h}}$ were $32 \%(P<0.001), 23 \%(P=0.005)$, and $19 \%(P=0.018)$ higher after $1.8,1.2$, and $0.6 \mathrm{mg}$ liraglutide treatment, respectively, than after placebo. The estimates of $C_{0}$ were $49 \%$ $(P<0.001), 41 \%(P>0.001)$, and 28\% $(P=0.008)$ higher after $1.8,1.2$, and $0.6 \mathrm{mg}$ liraglutide treatment, respectively (Table 2 ), suggesting a potential dose-dependent increase in insulin response. Estimates of insulin $A U C_{0-1 \mathrm{~h}}$ and i $A U C_{0-5 \mathrm{~h}}$ were not significantly different from placebo at any of the liraglutide doses investigated (Table 2).

\section{Gastric Emptying}

Estimates of paracetamol $A U C_{0-5 \mathrm{~h}}$ were only significantly lower (17\%) with liraglutide $1.2 \mathrm{mg}$, with no significant differences observed with liraglutide $0.6 \mathrm{mg}(6 \% ; P=0.287)$ or liraglutide $1.8 \mathrm{mg}$ (6\%; $P=0.301)$. Compared with placebo, estimates of paracetamol $A U C_{0-1 \mathrm{~h}}$ and $C_{\max }$ were significantly lower (by $43 \%$ and $30 \%$ for $A U C_{0-1}$, and $31 \%$ and $23 \%$ for $C_{\max }$ ) at the two higher liraglutide doses (1.2 and $1.8 \mathrm{mg}$, respectively), indicating a delay in gastric emptying with liraglutide during the early phase after the breakfast meal (Table 3). There was no significant delay with liraglutide $0.6 \mathrm{mg}$. 
Figure 3. Mean postprandial plasma insulin concentration profiles during a meal test performed at steady-state liraglutide doses of $0.6,1.2$, and $1.8 \mathrm{mg}$ or placebo.

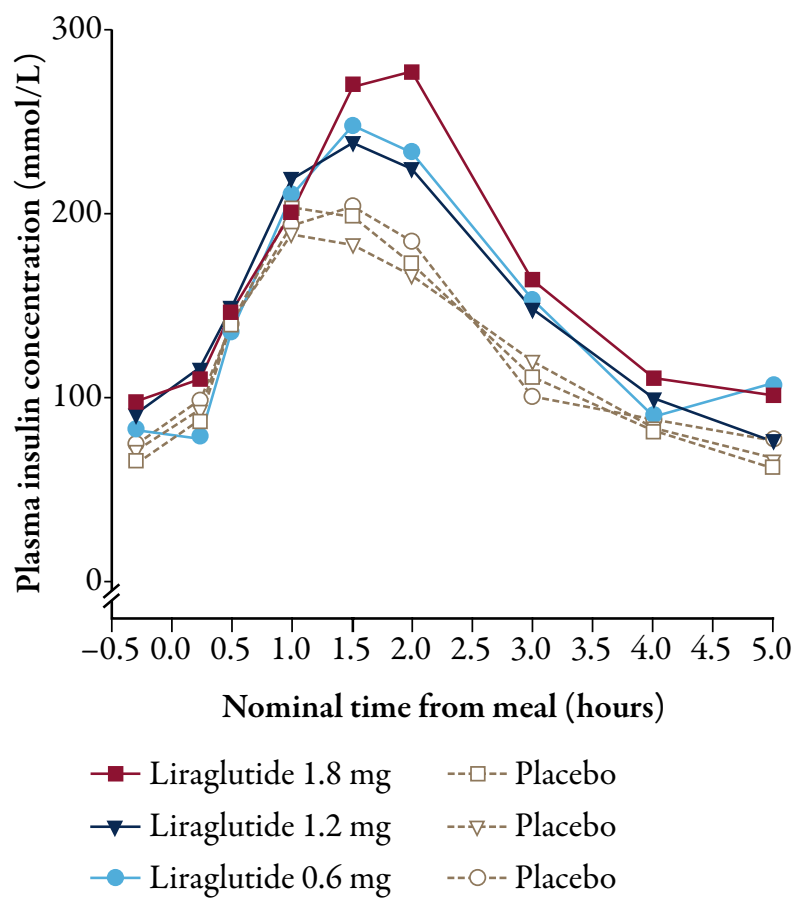

\section{Exploratory Analysis Between Glucose and Gastric Emptying}

A positive association between glucose $\mathrm{i} A U C_{0-1 \mathrm{~h}}$ and paracetamol $\log \left(A U C_{0-1 \mathrm{~h}}\right)$ was seen regardless of treatment (placebo/liraglutide); that is, the more the paracetamol response was reduced, the more glucose response was also reduced. Furthermore, for any given paracetamol response, there was a lower glucose $\mathrm{i} A U C_{0-1 \mathrm{~h}}$ for liraglutide treatment than for placebo. When compared with placebo, liraglutide significantly lowered $\mathrm{i} A U C_{0-1 \mathrm{~h}}$ at all doses, even when the effect of gastric emptying was removed by statistical adjustment; that is, glucose $\mathrm{i} A U C_{0-1 \mathrm{~h}}$ was adjusted for the effect of paracetamol $\log \left(A U C_{0-1 \mathrm{~h}}\right)$ as a covariate. After adjustment, the mean PPG excursions, as assessed by estimates of $\mathrm{i} A U C_{0-5 \mathrm{~h}} / 5$ hours, were $0.64 \mathrm{mmol} / \mathrm{L}(P=0.001), 0.65 \mathrm{mmol} / \mathrm{L}$ $(P=0.002)$, and $0.38 \mathrm{mmol} / \mathrm{L}(P=0.002)$ lower after liraglutide $1.8,1.2$, and $0.6 \mathrm{mg}$ treatment, respectively, than after placebo.

\section{Safety}

Liraglutide was well tolerated. There were no withdrawals due to AEs and no hypoglycemic episodes or serious adverse events (SAEs) were reported during the trial period. A total of 18 AEs were reported by nine subjects, the majority of which were mild. The same number of AEs (seven mild and two moderate) emerged during liraglutide and placebo treatments. The most frequent AEs were: headache (one reported with liraglutide treatment and three with placebo); gastrointestinal (GI) disorders (two mild dyspepsia events and one other GI disorder reported with liraglutide, and one diarrhea and one nausea event reported with placebo); and infections (three reported with liraglutide and two with placebo). There were no changes reported in physical examinations, vital signs, or ECGs, and no trends for changes in any of the laboratory parameters were identified.

\section{DISCUSSION}

This study has supported our hypothesis that treatment with liraglutide results in reductions in absolute and incremental PPG levels compared with placebo. Following 3 weeks of liraglutide treatment, the PPG response $\left(A U C_{0-5 \mathrm{~h}}\right)$ was reduced by $38 \%$, glucose excursions above baseline levels were reduced by $1.1 \mathrm{mmol} / \mathrm{L}$ on average, and the mean 2-hour PPG was lower than the 2-hour PPG goal ( $<10 \mathrm{mmol} / \mathrm{L})$, as recommended by the American Diabetes Association (ADA). ${ }^{39}$ More than $70 \%$ of the liraglutide-treated patients achieved the ADA target.

The decrease in PPG was likely to be driven by two mechanisms. Firstly, the glucose- 
Table 2. Comparison of insulin endpoints.

\begin{tabular}{|c|c|c|c|c|}
\hline & \multirow{2}{*}{$\begin{array}{l}\text { Liraglutide } \\
\text { (mean [SD]) }\end{array}$} & \multirow{2}{*}{$\begin{array}{c}\text { Placebo } \\
(\text { mean [SD]) }\end{array}$} & \multicolumn{2}{|c|}{ Liraglutide versus placebo } \\
\hline & & & Estimate* $\left.^{*} 95 \% \mathrm{CI}\right)$ & $P$ value \\
\hline \multicolumn{5}{|c|}{ Fasting $C_{\text {insulin, } 0 \mathrm{~h}}(\mathrm{pmol} / \mathrm{L}) \dagger$} \\
\hline $0.6 \mathrm{mg}$ & $75.3(72.1)$ & $63.2(78.9)$ & $1.28(1.07,1.53)$ & 0.008 \\
\hline $1.2 \mathrm{mg}$ & $84.7(98.3)$ & $61.4(67.9)$ & $1.41(1.18,1.69)$ & $<0.001$ \\
\hline $1.8 \mathrm{mg}$ & $91.1(100.6)$ & $57.6(54.2)$ & $1.49(1.25,1.78)$ & $<0.001$ \\
\hline \multicolumn{5}{|c|}{$C_{\text {insulin, } \max }(\mathrm{pmol} / \mathrm{L}) \dagger$} \\
\hline $0.6 \mathrm{mg}$ & $257.9(129.0)$ & $210.6(140.3)$ & $1.19(1.01,1.40)$ & 0.034 \\
\hline $1.2 \mathrm{mg}$ & $255.0(151.7)$ & $213.5(115.3)$ & $1.15(0.98,1.35)$ & 0.085 \\
\hline $1.8 \mathrm{mg}$ & $301.4(227.2)$ & $217.8(140.8)$ & $1.26(1.07,1.48)$ & 0.006 \\
\hline \multicolumn{5}{|c|}{$A U C_{\text {insulin, } 0-1 \mathrm{~h}}(\mathrm{pmol} \mathrm{min} / \mathrm{L}) \dagger$} \\
\hline $0.6 \mathrm{mg}$ & $7981(5039)$ & $7709(6245)$ & $1.03(0.84,1.26)$ & 0.760 \\
\hline $1.2 \mathrm{mg}$ & $8190(6678)$ & $7534(5030)$ & $1.01(0.83,1.23)$ & 0.930 \\
\hline $1.8 \mathrm{mg}$ & $8421(6266)$ & $7469(4328)$ & $1.12(0.92,1.37)$ & 0.247 \\
\hline \multicolumn{5}{|c|}{$A U C_{\text {insulin, } 0-5 \mathrm{~h}}(\mathrm{pmol} \mathrm{min} / \mathrm{L}) \dagger$} \\
\hline $0.6 \mathrm{mg}$ & $45431(29696)$ & $37384(28068)$ & $1.19(1.03,1.37)$ & 0.018 \\
\hline $1.2 \mathrm{mg}$ & $47153(34386)$ & $36055(24126)$ & $1.23(1.07,1.42)$ & 0.005 \\
\hline $1.8 \mathrm{mg}$ & $50162(37537)$ & $36296(23799)$ & $1.32(1.14,1.52)$ & $<0.001$ \\
\hline \multicolumn{5}{|c|}{$\mathrm{i} A U C_{\text {insulin, } 0.5 \mathrm{~h}} / 5 \mathrm{~h}(\mathrm{pmol} / \mathrm{L}) \dagger$} \\
\hline $0.6 \mathrm{mg}$ & $77.4(47.6)$ & $62.7(26.2)$ & $10.4(-6.30,27.0)$ & 0.216 \\
\hline $1.2 \mathrm{mg}$ & $73.5(34.7)$ & $60.6(25.5)$ & $11.2(-5.45,27.9)$ & 0.181 \\
\hline $1.8 \mathrm{mg}$ & $78.5(44.8)$ & $64.7(30.5)$ & $12.0(-4.51,28.6)$ & 0.149 \\
\hline
\end{tabular}

${ }^{*}$ Estimates are ratios except $\mathrm{i} A U C_{\text {insulin, } 0-5 \mathrm{~h}} / 5 \mathrm{~h}$, which are differences.

+Conversion factor to $\mu \mathrm{IU} / \mathrm{mL}: \times 0.144$.

$A U C=$ area under the curve; $C_{\text {insulin }}=$ concentration of insulin; $\mathrm{CI}=$ confidence intervals; $\mathrm{SD}=$ standard deviation.

dependent insulinotropic effect of liraglutide, as postprandial insulin levels were increased after treatment with liraglutide. Additionally, the delay in gastric emptying observed with liraglutide treatment is likely to play a role, as transition of nutrients from the stomach to the small intestine is the rate-limiting step for glucose absorption and, therefore, is an important factor in determining PPG excursions. ${ }^{40}$ In this study, it was observed that for any given gastric emptying rate, incremental PPG levels were reduced with liraglutide treatment compared with placebo. Together with the fact that the glucose-lowering effect of liraglutide was still significant after adjusting for the effect of gastric emptying, this suggests that gastric emptying accounts for part, but not all, of the glucose-lowering effect of liraglutide.

In this study, the paracetamol absorption method was chosen to determine the rate of gastric emptying. The limitations of this technique have been described previously; ${ }^{41,42}$ however, a relatively recent report, ${ }^{36}$ has concluded that the paracetamol absorption method does produce results that are comparable to the "goldstandard" gastric emptying scintigraphy (GES) methodology. ${ }^{43-45}$ It is therefore considered that while alternative methodologies are available, such as GES, and ${ }^{13} \mathrm{C}$ acetate breath tests, ${ }^{13}$ the paracetamol absorption test is a suitable and 
Table 3. Comparison of gastric emptying as assessed by plasma paracetamol endpoints.

\begin{tabular}{|c|c|c|c|c|}
\hline & \multirow{2}{*}{$\begin{array}{l}\text { Liraglutide } \\
\text { (mean }[S D])\end{array}$} & \multirow{2}{*}{$\begin{array}{c}\text { Placebo } \\
\text { (mean }[S D])\end{array}$} & \multicolumn{2}{|c|}{ Liraglutide versus placebo } \\
\hline & & & Estimate* $^{*}(95 \% \mathrm{CI})$ & $P$ value \\
\hline \multicolumn{5}{|c|}{$A U C_{\text {paracetamol, } 0-1 \mathrm{~h}}(\mu \mathrm{g} \min / \mathrm{mL})$} \\
\hline $0.6 \mathrm{mg}$ & $605(270)$ & $747(302)$ & $0.78(0.57,1.07)$ & 0.125 \\
\hline $1.2 \mathrm{mg}$ & $547(310)$ & $771(237)$ & $0.57(0.42,0.78)$ & $<0.001$ \\
\hline $1.8 \mathrm{mg}$ & $558(265)$ & $729(225)$ & $0.70(0.51,0.96)$ & 0.028 \\
\hline \multicolumn{5}{|c|}{$A U C_{\text {paracetamol, } 0.5 \mathrm{~h}}(\mu \mathrm{g} \mathrm{min} / \mathrm{mL})$} \\
\hline $0.6 \mathrm{mg}$ & $2480(612)$ & $2644(668)$ & $0.94(0.83,1.06)$ & 0.287 \\
\hline $1.2 \mathrm{mg}$ & $2276(721)$ & $2645(604)$ & $0.83(0.74,0.94)$ & 0.003 \\
\hline $1.8 \mathrm{mg}$ & $2476(657)$ & $2573(480)$ & $0.94(0.84,1.06)$ & 0.301 \\
\hline \multicolumn{5}{|c|}{$C_{\max }(\mu \mathrm{g} / \mathrm{mL})$} \\
\hline $0.6 \mathrm{mg}$ & $17.0(6.1)$ & $19.0(7.9)$ & $0.90(0.75,1.07)$ & 0.226 \\
\hline $1.2 \mathrm{mg}$ & $15.3(6.2)$ & $21.0(5.3)$ & $0.69(0.58,0.82)$ & $<0.001$ \\
\hline $1.8 \mathrm{mg}$ & $15.2(5.3)$ & $19.3(6.7)$ & $0.77(0.64,0.92)$ & 0.004 \\
\hline
\end{tabular}

${ }^{*}$ Estimates are ratios.

$A U C=$ area under the curve; $C_{\max }=$ maximum concentration; $\mathrm{CI}=$ confidence intervals; $\mathrm{SD}=$ standard deviation.

accurate method for determining the rate of gastric emptying, with respect to currently used methodologies.

Previous reports ${ }^{13}$ have indicated that administration of GLP-1 results in a dosedependent reduction in the rate of gastric emptying. Such a dose-dependent response with liraglutide in this study was not observed; although the rate of gastric emptying for subjects treated with liraglutide was greater than for those receiving placebo, despite only showing significance for treatment with $1.2 \mathrm{mg}$ liraglutide and above. However, a dosedependent effect upon glucose concentration was observed, which was significant at all three dose levels of liraglutide. It should be noted that because liraglutide dosing was not randomized in this study and the trial was designed primarily to compare maximal liraglutide dosages upon gastric emptying and glycemic control, any comparisons relating to the effects of liraglutide dosages should be considered purely explorative. Nevertheless, these observations support the theory that gastric emptying only partly accounts for the glucose-lowering effect of liraglutide. This is in accordance with other results showing that gastric emptying accounts for about $34 \%$ of the variance in glucose response after an oral glucose load in healthy subjects. ${ }^{46}$ It should be recognized that the slowing of gastric emptying by liraglutide in the present study occurs despite a lowering of blood glucose, which has been shown to favor more rapid gastric emptying. ${ }^{47}$

The study by Meier et al., ${ }^{13}$ showing a dosedependent reduction in gastric emptying, was performed acutely, whereas in the present study, subjects had a preceding period with liraglutide treatment. Studies with chronic administration of GLP-1 suggest the possibility of tachyphylactic effect upon gastric emptying; ${ }^{48}$ however, this study was not of sufficient duration to assess this appropriately. Nonclinical data suggest that, after 2 weeks' treatment, the effect of liraglutide is reduced on gastric emptying, but its positive effect on body weight persists. ${ }^{49}$ Furthermore, liraglutide's effect on glycemic control is long lasting. ${ }^{26-33}$ 
Exenatide has also been shown to significantly reduce PPG levels and to slow gastric emptying in subjects with type 2 diabetes. ${ }^{50}$ These results, obtained using the method of paracetamol absorption, have subsequently been confirmed using the alternative method of scintigraphy to determine gastric emptying. ${ }^{51}$

Due to the short duration of exposure $\left(t_{1 / 2}\right.$ $\sim 2.4 \mathrm{~h}$ ), deceleration of gastric emptying and improvements in postprandial glycemia with twice-daily exenatide are most pronounced at the meals before which exenatide has been given..$^{51,52}$ In contrast, treatment with once-daily liraglutide and once-weekly exenatide provides 24 hours' exposure to therapeutic drug concentrations. This difference in the pharmacokinetics may be the reason why once-weekly exenatide provides postprandial glycemic control with all meals, ${ }^{53}$ in contrast to twice-daily exenatide. A similar effect may be expected for liraglutide.

Liraglutide treatment increased the fasting insulin response compared with placebo, indicating a potential increase in beta-cell function, consistent with the findings of a previous study with liraglutide. ${ }^{54}$ In addition, maximum postprandial insulin concentrations increased and incremental insulin AUC remained unchanged in the postprandial period with liraglutide treatment, compared with placebo, despite lower PPG concentrations. Thus, relative to the reduced glucose concentrations, fasting and postprandial insulin responses may, in fact, be enhanced. Glucose-dependent insulin secretion therefore appears to be an important mechanism for reduction of both FPG and PPG levels. This is most likely explained by the ability of liraglutide to restore the incretin response, which is partially lost in patients with type 2 diabetes. ${ }^{55}$

In contrast to the findings in the present study with liraglutide, the postprandial insulin response with exenatide was reduced compared with placebo, suggesting that delayed gastric emptying plays a substantial role in the improvement of PPG after exenatide. ${ }^{50}$ Exenatide should be dosed twice-daily within 60 minutes prior to two major meals of the day, and improves postprandial glycemic control of these meals. ${ }^{52,56}$ Due to a longer $t_{1 / 2}$, liraglutide exposure covers 24 hours and can be administered once-daily, independent of meal times. ${ }^{57}$

In this study, liraglutide was well tolerated. No hypoglycemic events were reported, which is in line with the glucose-dependent insulinotropic effect of liraglutide. The AE profiles were comparable to placebo. There were no withdrawals from treatment and no safety concerns were raised.

\section{CONCLUSION}

This study has shown that liraglutide treatment is well tolerated and effective in lowering both absolute and incremental PPG as well as FPG levels after short-term treatment. The effects of liraglutide on postprandial glycemic control are likely to be mediated by a combination of increased insulin secretion and an early postprandial delay in gastric emptying.

\section{ACKNOWLEDGMENTS}

We thank the investigators and their staff for the conduct of this study and the volunteers for their participation. The authors accept direct responsibility for this paper and are grateful for the contribution made by Dr Angela Pozo Romajo of Watermeadow Medical, Witney, UK (supported by Novo Nordisk A/S, Bagsvaerd, Denmark) in developing the draft manuscript from an agreed outline, and in collating comments.

$\mathrm{AF}, \mathrm{CH}$, and $\mathrm{MZ}$ are employed by Novo Nordisk and hold stocks in the company. CK received financial support for conducting this study from Novo Nordisk A/S, the developer of liraglutide. 
$\mathrm{AF}$ is the guarantor for this article, and takes responsibility for the integrity of the work as a whole.

Open Access. This article is distributed under the terms of the Creative Commons Attribution Noncommercial License which permits any noncommercial use, distribution, and reproduction in any medium, provided the original author(s) and source are credited.

\section{REFERENCES}

1. Gerich JE. The genetic basis of type 2 diabetes mellitus: impaired insulin secretion versus impaired insulin sensitivity. Endocr Rev. 1998;19:491-503.

2. Knop FK, Vilsbøll T, Højberg PV, et al. Reduced incretin effect in type 2 diabetes: cause or consequence of the diabetic state? Diabetes. 2007;56:1951-1959.

3. Nauck M, Stöckmann F, Ebert R, Creutzfeldt W. Reduced incretin effect in type 2 (non-insulindependent) diabetes. Diabetologia. 1986;29:46-52.

4. UK Prospective Diabetes Study (UKPDS) Group. Intensive blood-glucose control with sulphonylureas or insulin compared with conventional treatment and risk of complications in patients with type 2 diabetes (UKPDS 33). Lancet. 1998;352:837-853.

5. Stratton IM, Adler AI, Neil HA, et al. Association of glycaemia with macrovascular and microvascular complications of type 2 diabetes (UKPDS 35): prospective observational study. BMJ. 2000;321:405-412.

6. Monnier L, Lapinski H, Colette C. Contributions of fasting and postprandial plasma glucose increments to the overall diurnal hyperglycemia of type 2 diabetic patients: variations with increasing levels of $\mathrm{HbA}(1 \mathrm{c})$. Diabetes Care. 2003;26:881-885.

7. Ceriello A, Colagiuri S, Gerich J, Tuomilehto J. Guideline for management of postmeal glucose. Nutr Metab Cardiovasc Dis. 2008;18:S17-S33.

8. Elrick H, Stimmler L, Hlad CJ, Arai Y. Plasma insulin responce to oral and intravenous glucose administration. J Clin Endocrinol Metab. $1964 ; 24: 1076-1082$.
9. Creutzfeldt W. The incretin concept today. Diabetologia. 1979;16:75-85.

10. Schirra J, Nicolaus M, Roggel R, et al. Endogenous glucagon-like peptide 1 controls endocrine pancreatic secretion and antro-pyloro-duodenal motility in humans. Gut. 2006;55:243-251.

11. Delgado-Aros S, Kim D, Burton DD, et al. Effect of GLP-1 on gastric volume, emptying, maximum volume ingested, and postprandial symptoms in humans. Am J Physiol Gastrointest Liver Physiol. 2002;282:G424-G431.

12. Nauck MA, Niedereichholz $U$, Ettler $R$, et al. Glucagon-like peptide 1 inhibition of gastric emptying outweighs its insulinotropic effects in healthy humans. Am J Physiol. 1997;273:E981-E988.

13. Meier JJ, Gallwitz B, Salmen S, et al. Normalization of glucose concentrations and deceleration of gastric emptying after solid meals during intravenous glucagon-like peptide 1 in patients with type 2 diabetes. J Clin Endocrinol Metab. 2003;88:2719-2725.

14. Meier JJ, Gethmann A, Götze O, et al. Glucagonlike peptide 1 abolishes the postprandial rise in triglyceride concentrations and lowers levels of non-esterified fatty acids in humans. Diabetologia. 2006;49:452-458.

15. Verdich C, Flint A, Gutzwiller JP, et al. A metaanalysis of the effect of glucagon-like peptide-1 (736) amide on ad libitum energy intake in humans. J Clin Endocrinol Metab. 2001;86:4382-4389.

16. Schirra J, Wank U, Arnold R, Göke B, Katschinski M. Effects of glucagon-like peptide-1(7-36)amide on motility and sensation of the proximal stomach in humans. Gut. 2002;50:341-348.

17. Schirra J, Houck P, Wank U, Arnold R, Göke B, Katschinski M. Effects of glucagon-like peptide-1(7-36)amide on antro-pyloro-duodenal motility in the interdigestive state and with duodenal lipid perfusion in humans. Gut. 2000;46:622-631.

18. Anvari M, Paterson CA, Daniel EE, McDonald TJ. Effects of GLP-1 on gastric emptying, antropyloric motility, and transpyloric flow in response to a nonnutrient liquid. Dig Dis Sci. 1998;43:1133-1140.

19. DeFronzo RA, Okerson T, Viswanathan P, Guan X, Holcombe JH, MacConell L. Effects of exenatide versus sitagliptin on postprandial glucose, insulin and glucagon secretion, gastric emptying, and 
caloric intake: a randomized, cross-over study. Curr Med Res Opin. 2008;24:2943-2952.

20. Juhl CB, Hollingdal M, Sturis J, et al. Bedtime administration of NN2211, a long-acting GLP-1 derivative, substantially reduces fasting and postprandial glycemia in type 2 diabetes. Diabetes. 2002;51:424-429.

21. Nauck MA, Heimesaat MM, Orskov C, Holst JJ, Ebert R, Creutzfeldt W. Preserved incretin activity of glucagon-like peptide 1 [7-36 amide] but not of synthetic human gastric inhibitory polypeptide in patients with type-2 diabetes mellitus. J Clin Invest. 1993;91:301-307.

22. Willms B, Werner J, Holst JJ, Orskov C, Creutzfeldt W, Nauck MA. Gastric emptying, glucose responses, and insulin secretion after a liquid test meal: effects of exogenous glucagon-like peptide-1 (GLP1)-(7-36) amide in type 2 (noninsulin-dependent) diabetic patients. J Clin Endocrinol Metab. 1996;81:327-332.

23. Drucker DJ, Nauck MA. The incretin system: glucagon-like peptide-1 receptor agonists and dipeptidyl peptidase- 4 inhibitors in type 2 diabetes. Lancet. 2006;368:1696-1705.

24. Vilsbøll T. Liraglutide: a once-daily GLP-1 analogue for the treatment of type 2 diabetes mellitus. Expert Opin Investig Drugs. 2007;16:231-237.

25. Agersø H, Jensen LB, Elbrønd B, Rolan P, Zdravkovic $\mathrm{M}$. The pharmacokinetics, pharmacodynamics, safety and tolerability of NN2211, a new longacting GLP-1 derivative, in healthy men. Diabetologia. 2002;45:195-202.

26. Nauck M, Hompesch M, Filipczak R, Le T, Zdravkovic M, Gumprecht J. Five Weeks of Treatment with the GLP-1 Analogue Liraglutide Improves Glycaemic Control and Lowers Body weight in Subjects with Type 2 Diabetes. Exp Clin Endocrinol Diabetes. 2006;114:417-423.

27. Vilsbøll T, Zdravkovic M, Le-Thi T, et al. Liraglutide, a long-acting human glucagon-like peptide-1 analog, given as monotherapy significantly improves glycemic control and lowers body weight without risk of hypoglycemia in patients with type 2 diabetes. Diabetes Care. 2007;30:1608-1610.

28. Marre $M$, Shaw J, Brändle $M$, et al. Liraglutide, a once-daily human GLP-1 analogue, added to a sulphonylurea over 26 weeks produces greater improvements in glycaemic and weight control compared with adding rosiglitazone or placebo in subjects with Type 2 diabetes (LEAD-1 SU). Diabet Med. 2009;26:268-278.
29. Nauck M, Frid A, Hermansen K, et al. Efficacy and safety comparison of liraglutide, glimepiride, and placebo, all in combination with metformin, in type 2 diabetes: the LEAD (liraglutide effect and action in diabetes)-2 study. Diabetes Care. 2009;32:84-90.

30. Garber A, Henry R, Ratner R, et al. Liraglutide versus glimepiride monotherapy for type 2 diabetes (LEAD-3 Mono): a randomised, 52-week, phase III, double-blind, parallel-treatment trial. Lancet. 2009;373:473-481.

31. Zinman B, Gerich J, Buse JB, et al. Efficacy and safety of the human glucagon-like peptide-1 analog liraglutide in combination with metformin and thiazolidinedione in patients with type 2 diabetes (LEAD-4 Met+TZD). Diabetes Care. 2009;32:12241230 .

32. Russell-Jones D, Vaag A, Schmitz O, et al. Liraglutide vs insulin glargine and placebo in combination with metformin and sulfonylurea therapy in type 2 diabetes mellitus (LEAD5 met+SU): a randomised controlled trial. Diabetologia. 2009;52:2046-2055.

33. Buse JB, Rosenstock J, Sesti G, et al. Liraglutide once a day versus exenatide twice a day for type 2 diabetes: a 26-week randomised, parallel-group, multinational, open-label trial (LEAD-6). Lancet. 2009;374:39-47.

34. WMA General Assembly. WMA Declaration of Helsinki - Ethical Principles for Medical Research Involving Human Subjects. Available at: http:// www.wma.net/en/30publications/10policies/b3/ index.html. Accessed January 21, 2011.

35. Willems M, Quartero AO, Numans ME. How useful is paracetamol absorption as a marker of gastric emptying? A systematic literature study. Dig Dis Sci. 2001;46:2256-2262.

36. Glerup H, Bluhme $H$, Villadsen GE, Rasmussen $\mathrm{K}$, Ejskjaer N, Dahlerup JF. Gastric emptying: a comparison of three methods. Scand J Gastroenterol. 2007;42:1182-1186.

37. Andersen L, Dinesen B, Jørgensen PN, Poulsen F, Røder ME. Enzyme immunoassay for intact human insulin in serum or plasma. Clin Chem. 1993;39:578-582.

38. Le Floch JP, Baudin E, Escuyer P, Wirquin E, Yomtov B, Perlemuter L. Reproducibility of glucose and insulin responses to mixed meal in type II diabetic patients. Diabetes Care. 1991;14:138-140. 
39. ADA. Standards of medical care in diabetes-2008. Diabetes Care. 2008;31(suppl. 1):S12-S54.

40. Green GM, Guan D, Schwartz JG, Phillips WT. Accelerated gastric emptying of glucose in Zucker type 2 diabetic rats: role in postprandial hyperglycaemia. Diabetologia. 1997;40:136-142.

41. Näslund E, Barkeling B, King N, et al. Energy intake and appetite are suppressed by glucagonlike peptide-1 (GLP-1) in obese men. Int J Obes Relat Metab Disord. 1999;23:304-311.

42. Little TJ, Pilichiewicz AN, Russo A, et al. Effects of intravenous glucagon-like peptide-1 on gastric emptying and intragastric distribution in healthy subjects: relationships with postprandial glycemic and insulinemic responses. J Clin Endocrinol Metab. 2006;91:1916-1923.

43. Horowitz M, Dent J. Disordered gastric emptying: mechanical basis, assessment and treatment. Baillières Clin Gastroenterol. 1991;5:371-407.

44. Collins PJ, Horowitz M, Cook DJ, Harding PE, Shearman DJ. Gastric emptying in normal subjects - a reproducible technique using a single scintillation camera and computer system. Gut. 1983;24:1117-1125.

45. Jones KL, Russo A, Berry MK, Stevens JE, Wishart JM, Horowitz M. A longitudinal study of gastric emptying and upper gastrointestinal symptoms in patients with diabetes mellitus. Am J Med. 2002;113:449-455.

46. Horowitz M, Edelbroek MA, Wishart JM, Straathof JW. Relationship between oral glucose tolerance and gastric emptying in normal healthy subjects. Diabetologia. 1993;36:857-862.

47. Schvarcz E, Palmér M, Aman J, Horowitz M, Stridsberg M, Berne C. Physiological hyperglycemia slows gastric emptying in normal subjects and patients with insulin-dependent diabetes mellitus. Gastroenterology. 1997;113: 60-66.

48. Spechler SJ, Wan HH, Chey YY. GERD versus $H$. pylori infections as potential causes of inflammation in the gastric cardia. Gastroenterology. 1997;112:A297.

49. Knudsen LB, Jelsing J, Vrang N, Tang-Christensen M, Raun K. Frequency and magnitude of antibody formation are lower with liraglutide than exenatide: LEAD-6 results. Diabetes. 2010;59:A161. Abstract 591-P.

50. Kolterman OG, Buse JB, Fineman MS, et al. Synthetic exendin-4 (exenatide) significantly reduces postprandial and fasting plasma glucose in subjects with type 2 diabetes. J Clin Endocrinol Metab. 2003;88:3082-3089.

51. Linnebjerg H, Park S, Kothare PA, et al. Effect of exenatide on gastric emptying and relationship to postprandial glycemia in type 2 diabetes. Regul Pept. 2008;151:123-129.

52. Bunck MC, Cornér A, Eliasson B, et al. One-year treatment with exenatide vs. insulin glargine: effects on postprandial glycemia, lipid profiles, and oxidative stress. Atherosclerosis. 2010;212:223-229.

53. Kim D, MacConell L, Zhuang D, et al. Effects of once-weekly dosing of a long-acting release formulation of exenatide on glucose control and body weight in subjects with type 2 diabetes. Diabetes Care. 2007;30:1487-1493.

54. Vilsbøll T, Brock B, Perrild H, et al. Liraglutide, a once-daily human GLP-1 analogue, improves pancreatic B-cell function and arginine-stimulated insulin secretion during hyperglycaemia in patients with Type 2 diabetes mellitus. Diabetic Med. 2008;25:152-156.

55. Kjems LL, Holst JJ, Vølund A, Madsbad S. The influence of GLP-1 on glucose-stimulated insulin secretion: effects on beta-cell sensitivity in type 2 and nondiabetic subjects. Diabetes. 2003;52:380-386.

56. Amylin Pharmaceuticals. Byetta Package insert. 2009. Available at: http://pi.lilly.com/us/byetta-pi. pdf. Accessed January 21, 2011.

57. Novo Nordisk. Victoza ${ }^{\circledR}$ prescribing information. 2010. Available at: http://www.victoza.com/pdf/ Victoza_ComboPI_5.24.pdf. Accessed January 21, 2011. 